[Agr. Biol. Chem., Vol. 25, No. 2, p. 83 87, 1961]

\title{
Studies on the Metabolism of Monofluoroacetate in the Liver of a Frog
}

\author{
By Kazuo Miura, Takao Uchiyama and Koichiro Honda \\ Laboratory of Biochemistry, College of Agriculture, University of Osaka Prefecture \\ Received July 8, 1960
}

\begin{abstract}
Many workers found that the poisoning animals with sodium fluoroacetate led quickly to a marked increase of citrate in the various tissues, but it failed to find such result in the liver in vivo as well as in vitro. In the liver of a frog, however, an accumulation of a large amount of citric acid was found 6 hours after the poison was orally administered to the animal. To decide whether the accumulation of citric acid in the liver of a frog is due to the formation of fluorocitrate in the liver itself or to the transport of fluorocitrate formed in other organs into the liver, we carried out the experiments using the mitochondrial particles prepared from a frog liver. And it was found that the oxygen uptake of mitochondria was inhibited and that the citrate synthesis of the particle increased by the addition of fluoroacetate with pyruvate and malate as substrates.
\end{abstract}

\section{INTRODUCTION}

The administration of sodium fluoroacetate to an animal has been shown to result in the accumulation of a large amount of citric acid in certain tissues ${ }^{1 \sim 3)}$. Peters et al.4) demonstrated that the accumulation of citric acid was due to the synthesis of fluorocitric acid, which blocked the tricarboxylic acid cycle at the aconitase stage. The specificity of this inhibition was clearly demonstrated by Peters and Morrison ${ }^{5)}$ on the highly purified aconitase ${ }^{6}$. Many studies on the metabolism of fluoroacetate in various organs have been done, but some questions remained to be answered. One of the important questions is concerning the liver. For instance, no increase

\footnotetext{
1) P. Buffa and R.A. Peters, J. Physiol., 110, 488 (1949).

2) A. Lindenbaum, M.R. White and J. Schubert, J. Biol. Chem., 190, 585 (1951).

3) K. Miura, S. Otsuka and K. I Ionda, This Journal 20, 219 (1956).

4) R.A. Peters, R.W. Wakelin, P. Buffa and I.C. Thomas, Proc. Roy. Soc. B., 140, 497 (1953).

5) J.F. Morrison and R.A. Peters, Biochem. J., 58, 437 (1954).

6) J.F. Morrison, Biochem. J., 56, 100 (1954).
}

of citric acid has been found in the liver of an animal poisoned with sodium fluoroacetate $^{1,3)}$. Peters et $\mathrm{al}^{7}$ ) and $\mathrm{Brady}^{8}$ ) reported that the system prepared from a pigeon liver, which contained the acetate-activatingenzyme $^{9)}$ and the condensing enzyme ${ }^{10}$ ) did not form fluorocitrate from fluoroacetate and oxalacetate. Peters ${ }^{11)}$, thereafter, found that citrate was accumulated in most tissues including the liver of a rat which received synthetic fluorocitrate. From these results, Peters concluded that fluoroacetate could not be activated in a mammalian liver and could not be metabolized to fluorocitrate. On the other hand, from the determination of the differences between the amounts of "citric acid" or "acethydroxamic acid" formed by the pigeon liver enzymes with fluoroacetate and those

\footnotetext{
7) R.A. Peters, Brit. Med. J., (2), 1165 (1952).

8) R.O. Brady, J. Biol. Chem., 217, 213 (1955)

9) T.C. Chou and F. Lipmann, Ibid., 196, 89 (1952).

10) S. Ochoa, J. R. Stern and M.C. Schneider, Ibid., 193, 691 (1951).

11) E.M. Gal, R.A. Peters and R.W. Wakelin, Biochem. J., 64, 161 (1956).
} 
without fluoroacetate, Elliott et al. ${ }^{12)}$ pointed out that fluoroacetate must be activated in the liver. Up to date, therefore, the metabolism of the poison in the liver has remained equivocal. We took a deep interest in throwing light on the mechanism of detoxification of the fluoroacetate poisoning. When sodium fluoroacetate is orally administered to an animal, it is expected that fluoroacetate, presumably in the same manner as acetate, would be absorbed by small intestine and transported through the portal vein into the liver, where many substances are metabolized and various kinds of poison are detoxificated. Therefore, we wish to investigate whether fluoroacetate can be metabolized in the liver or not. To clarify these questions, some experiments have been carried out. This report is concerned with the poisoning of the liver of frog by fluoroacetate in vivo and in vitro.

\section{EXPERIMENTAL}

Female frogs, Rana nigromacurata, of about $80 \mathrm{~g}$ were used except in the preliminary experiments when female bullfrog, Rana catesbyana, of $210 \sim 240 \mathrm{~g}$ were used exclusively.

In the experiments in vivo, the animal received a single oral dose of aqueous sodium fluoroacetate solution. After the animals were sacrificed by spinal wreckage, the livers were immediately removed, weighed and ground in a mortar with quarz sand by adding $15 \%$ trichloroacetic acid solution, and then the homogenate was diluted to $10 \mathrm{ml}$ by washing with the acid solution. The citrate in the mixture was estimated according to the method of McArdle ${ }^{13)}$.

In the experiments in vitro, the enzyme solutions were prepared as follows: The liver was quickly removed and immersed in ice cold $0.7 \% \mathrm{KCl}$ solution containing $0.02 \mathrm{M} \mathrm{NaHCO}_{3}$. After a two minutes' stay in ice cold solution, they were weighed and cut into small pieces and then homogenized with the addition of the saline in Potter-Ervehjem homogenizer kept ice cold. When completely dispersed, the homogenate was squeezed through muslin and centrifuged for 10 minutes at 1,000 r.p.m. in a refrigated centrifuge. The

12) A. Marcus and W.B. Elliott, J. Biol. Chem., 218, 823 (1956).

13) B. McArdle, Biochem. J., 60, 647 (1955). supernatant brown-tinted suspension was centrifuged for 30 minutes at $8,000 \times \mathrm{g}$. The supernatant solution was stocked in a refrigerator as the soluble fraction. The precipitate was washed with 5 parts of ice cold $0.7 \% \mathrm{KCl}$ solution by centrifuging for 30 minutes at $8,000 \times \mathrm{g}$, and the washed precipitate was suspended in the saline buffered by $0.05 \mathrm{M}$ potassium phosphate pH 7.4.

One $\mathrm{ml}$ of the enzyme solution was pipetted into a respiratory vessel surrounded by ice and already containing $0.2 \mathrm{ml}$ of $0.198 \mathrm{M}$ sodium DL-malate, $0.1 \mathrm{ml}$ of $0.198 \mathrm{~m}$ sodium pyruvate, $2 \mathrm{mg}$ of ATP (Na salt), $0.1 \mathrm{ml}$ of $39.9 \mathrm{mM}$ magnesium chloride, $0.2 \mathrm{ml}$ of $0.5 \mathrm{M}$ potassium phosphate buffer $\mathrm{pH} 7.4,0.2 \mathrm{ml}$ of $0.4995 \mathrm{M}$ sodium fluoroacetate and sufficient $0.7 \% \mathrm{KCl}$ solution was added to bring the volume to $3.0 \mathrm{ml}$ after adding both enzyme solution and substances. All the solutions used above, except ATP, were dissolved in $0.7 \%$ KCl solution.

Oxygen uptake was measured by manometric method in Warburg's respiratory apparatus at $30^{\circ} \mathrm{C}$.

After the reaction mixtures were incubated in Warburg's respiratory vessels for 75 minutes at $30^{\circ} \mathrm{C}$, the reaction was stopped by the addition of $15 \%$ trichloroacetic acid solution. The amount of citric acid in the mixture was estimated as described in the experiments in vivo ${ }^{13)}$.

Nitrogen in the enzyme solution was determined by the micro Kjeldahl method.

\section{RESULTS}

A frog has a resisting power to the monofluoroacetate poisoning, e.g., its $\mathrm{LD}_{50}$ is more than $500 \mathrm{mg} / \mathrm{kg}^{14)}$. In order to obtain a preliminary knowledge of metabolism of fluoroacetate in a frog, we determined the increase of citric acid in the liver, kidney and heart of a bullfrog, Rana catesbyana, orally received $500 \mathrm{mg}$ of sodium fluoroacetate. The results are shown in Table I. It indicates that a marked increase of citric acid was observed not only in the kidney and the heart but also in the liver.

To elucidate further the effects of fluoroacetate on the metabolism in the liver, experi-

14) B.S. Saunders, "Phosphorus and Fluorine", Cambridge Univ. Press, 1957, p. 137. 
Table I. The InCRease of Gitric ACID IN The LiVer, KidNEY AND Heart OF a BULlFrog, Rana catesbyana, ORALLY RECEIVED $500 \mathrm{mg}$ oF SODIUM FLuOROACETATE

\begin{tabular}{|c|c|c|c|c|c|c|}
\hline \multirow{2}{*}{$\begin{array}{c}\text { Exp. } \\
\text { no. }\end{array}$} & \multirow{2}{*}{$\begin{array}{l}\text { Time } \\
\text { (hrs.) }\end{array}$} & \multirow{2}{*}{$\begin{array}{l}\text { Body } \\
\text { weight } \\
\text { (g) }\end{array}$} & \multirow{2}{*}{$\begin{array}{c}\text { Dose } \\
(\mathrm{mg} / \mathrm{g})\end{array}$} & \multicolumn{3}{|c|}{$\begin{array}{c}\text { Citric acid }(\mu \mathrm{g} / \mathrm{g} \text { wet } \\
\text { tissue) }\end{array}$} \\
\hline & & & & Liver & Kidney & Heart \\
\hline 1 & & 220 & 0 & 52.4 & 20.0 & 40.0 \\
\hline 2 & & 225 & 0 & 42.5 & 18.7 & 51.0 \\
\hline 3 & 3 & 210 & 2.38 & 790 & 258 & 786 \\
\hline 4 & 3 & 215 & 2.33 & 1020 & 206 & 416 \\
\hline 5 & 24 & 240 & 2.08 & 940 & 428 & 580 \\
\hline
\end{tabular}

The animals were not fed for 10 days before the experiment.

ments using a frog, Rana nigromacurata, were carried out as follows:

Relations between the dose of sodium fluoroacetate and the citric acid accumulation in the liver of a frog, Rana nigromacurata

The frogs were sacrificed 3 hours after a single oral dose of sodium fluoroacetate was given. For each experiments 2 4 animals were used. The citric acid accumulation was shown in Fig. 1. The amount of citric acid in the livers increased twice as much as the normal value by the dosage of $10 \mathrm{mg} / \mathrm{kg}$ of the poison, and reached the maximum level, $1,000 \mu \mathrm{g} / \mathrm{g}$ wet tissue, by the dosage of 200 $\mathrm{mg} / \mathrm{kg}$. The maximum value in the liver of a frog poisoned is proportional to the value

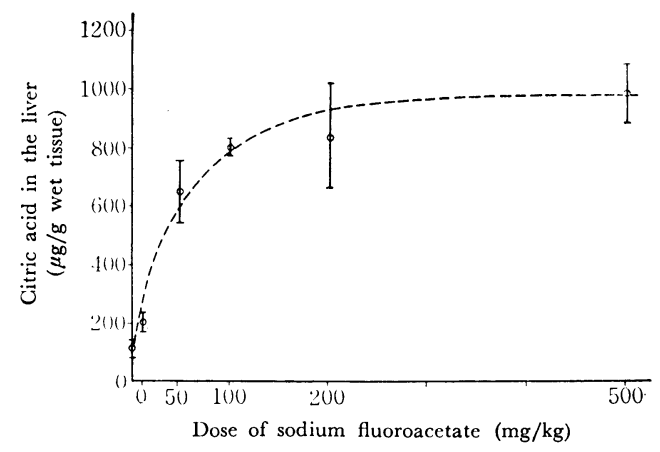

FIG. 1. The Relation between the Doses of Fluoroacetate and the Gitrate Accumulation in the Liver of a Frog, Rana nigromacurata.

Frogs were given a single oral dose of the poison and sacrificed at the end of three hours. The open cycles represent an average of $2 \sim 4$ separate determinations. Vertical bars represent the standard deviation. in the kidney of a rat poisoned with $1.2 \mathrm{mg} / \mathrm{kg}$ of fluoroacetate ${ }^{2}$.

No convulsions were observed in these animals.

Citrate concentration in the frog liver after the single dosage of sodium fluoroacetate

The amount of citric acid in the liver was estimated after the single oral dosage of $100 \mathrm{mg} / \mathrm{kg}$ of the poison. For each experiment 2 5 animals were used. The results were shown in Fig. 2. The citrate concentration in the liver increased three times 1 hour after poisoning, and reached the maximum level after 6 hours. In certain tissues of a rat poisoned with a sublethal dose of sodium fluoroacetate, citrate concentration was raised to the maximum level about 4 to 6 hours after poisoning and fell thereafter gradually and then reached the normal level after the lapse of 24 hours $^{2}$. In a frog liver, however, citrate concentration did not tend to fall even after the lapse of 24 hours. The convulsions were observed 2 of 4 animals used in the experiment of 24 hours' duration.

Inhibition of the oxygen uptake and accumulation of citrate of various liver fractions from frogs in the presence of sodium fluoroacetate with malate and pyruvate.

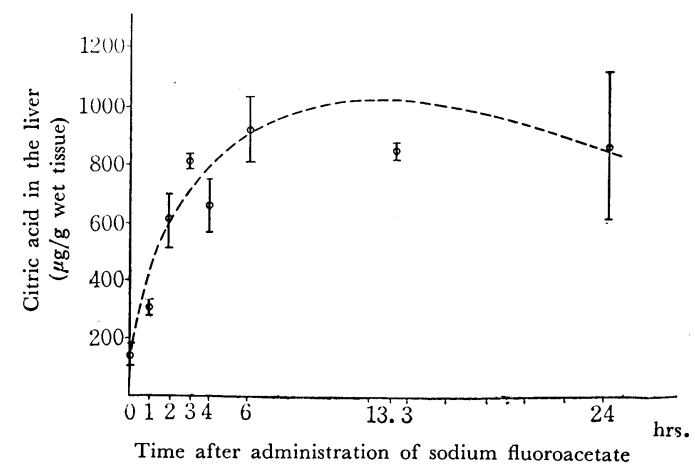

FIG. 2. Effects of Fluoroacetate on the Citrate Accumulation in the Liver of a Frog, Rana nigromacurata, after a Single Oral Dosage of $100 \mathrm{mg}$ of the Poison per kg.

The open cycles represent an average of $2 \sim 5$ separate determinations. The vertical bars represent the standard deviation. 
As described above, in the experiments in vivo, citrate was accumulated in the liver of a frog poisoned with sodium fluoroacetate. There was, however, a doubt that the accumulation might be due to the fluorocitrate transported from other organs such as a kidney or a heart where fluoroacetate could be activated, so the soluble enzyme fraction and mitochondrial particle fraction were prepared from a frog liver and it was examined whether the frog liver itself could form fluorocitrate from fluoroacetate.

TABle II. Formation OF Gitric ACID by Various Frog Liver ENZYMe Fractions Poisoned With Sodium Fluoroacetate in The PRESENCE OF Sodium Malate and Sodium Pyruvate as Substrates

Citric acid formed $(\mu \mathrm{g} / \mathrm{vessel})$

\section{Fraction} Control $33.3 \mathrm{mM}(\mathrm{mean})$
(mean) $\mathrm{FCH}_{2} \mathrm{COONa}$

$\begin{array}{lccc}\text { Particle } & 14(13) & 61(59) & 46 \\ \text { Soluble } & 12 & 57 & \\ & 1 & 1(1) & 0 \\ \text { Particle+Soluble } & - & 1 & \\ & 63(59) & 112(119) & 60 \\ & 56 & 126 & \end{array}$

The reaction mixture and procedure were described in the text. The particle fraction corresponds to $400 \mathrm{mg}$ of the tissue $/ \mathrm{ml}$, and its nitrogen was $0.627 \mathrm{mg} / \mathrm{ml}$. The soluble fraction corresponds to $150 \mathrm{mg}$ of the liver $/ \mathrm{ml}$, and its nitrogen was $1.344 \mathrm{mg} / \mathrm{ml}$.

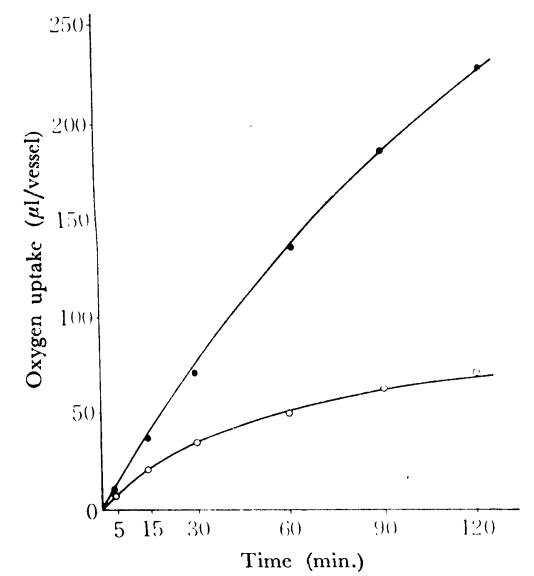

FIG. 3. Sociium Fluoroacetate as Inhibitor of the Oxidation of Malate by Frog Liver Particles. The reaction mixture is described in the text. The particle fraction corresponds to $250 \mathrm{mg} / \mathrm{ml}$.
Table II shows that citrate was accumulated in the particle fraction added by fluoroacetate but was not accumulated in the soluble fraction in the case where sodium malate and sodium pyruvate were used as substrates. And also Fig. 3 shows that the oxidation of the substrates by the particles was inhibited about $60 \%$ by the addition of sodium fluoroacetate (final concentration, $33.3 \mathrm{~mm}$ ).

\section{DISCUSSIONS}

Many investigators found no accumulation of citrate in the livers of most animals poisoned with sodium fluoroacetate. As shown above, however, a marked increase of citrate was found in the liver of a frog, Rana nigromacurata as well as Rana catesbyana poisoned with a single oral dose of sodium fluoroacetate. The experiments in vitro in which fluoroacetate inhibited the oxidation of malate and caused the accumulation of citrate in liver particles explained that the accumulation of citrate in a frog liver in vivo was due to fluorocitrate formed in the liver itself, that is, fluoroacetate was activated in the liver of a frog to fluoroacetyl CoA, followed by the condensation of the latter with oxalacetic acid to form fluorocitrate which blocked the tricarboxylic acid cycle at the aconitase stage.

The facts mentioned above suggested that fluoroacetate might be activated even in the mammalian liver where the fluoroacetyl moiety could tend to other metabolic pathway such as fluorinated acetoacetate synthesis8,15) or fluorinated lipid synthesis ${ }^{16)}$ than the formation of fluorocitrate.

\section{SUMMARY}

1) The effects of fluoroacetate on frog livers were studied in vivo and in vitro.

2) Fluoroacetate caused the accumulation of citrate in the liver of a frog in vivo as well

15) K. Miura and T. Hori, This Journal, 25, 94 (1961).

16) A.H. Phillips and R.G. Langdon, Arch. Biochem. Biophys., 58, 247 (1956). 
well as in vitro. The oxidation of malate by the frog liver particles was also inhibited by fluoroacetate.

3) The possibility of activation of fluoroacetate in the liver was discussed.
Acknowledgements The authors are indebted to Professor Makoto Kandatsu of University of Tokyo for his invaluable advice and encouragement.

[Agr. Biol. Chem., Vol. 25, No. 2, p. 87 93, 1961]

\title{
Studies on the Metabolism of Fluoroacetate in the Liver of a Rat: Part I. Effects of Insulin Administration upon the Metabolism of Fluoroacetate in the Liver of a Rat
}

\author{
By Kazuo Miura and Takao Uchiyama \\ Laboratory of Biochemistry, College of Agriculture, University of Osaka Prefecture \\ Received July 8, 1960
}

\begin{abstract}
In a rat poisoned with sodium fluoroacetate no accumulation of citrate was found in the liver, while in that of a frog fluoroacetate administration was found to cause a marked increase of citrate. In this paper, it was shown that even in a rat when it was treated with insulin before fluoroacetate administration, citrate accumulation could be found in the liver. In the experiments in vitro using slices of a rat liver it was also shown that fluoroacetate could cause an accumulation of citrate and inhibited the oxidation of malate in the slices of a normal as well as an insulinized liver.
\end{abstract}

\section{INTRODUCTION}

In our previous report, it was pointed out that fluoroacetate could be metabolized in a frog liver and cause the abnormal accumulation of citrate in the liver ${ }^{1)}$. These results led us to speculate that this phenomenon might be possible to occur in a mammalian reported that no accumulation of citrate occurred in a rat liver after administration of curred in a rat liver after administration of sodium fluoroacetate to the animal. From

1) K. Miura, T. Uchiyama and K. Honda, This Journal, 25, 83 (1961).

2) P. Buffa and R.A. Peters, J. Physiol., 110, 488 (1949).

3) V.R. Potter and H. Busch, Cancer Res., 10, 353 (1950). these facts, Peters ${ }^{4}$ ) concluded that fluoroacetate could not be activated and therefore, could not be metabolized in a mammalian liver.

But it might be possible to guess that no accumulation of citrate in a mammalian liver was caused by the fact that the metabolic pathways of fluoroacetate in a liver tend towards direction other than the tricarboxylic acid cycle. If the direction of metabolic pathways in a mammalian liver was changed by some method, it might be able to alternate 4) E.M. Gal, R.A. Peters and R.W. Wakelin, Biochem. J., 64, 161 (1956). 